\title{
A Comparative Study of the Distribution of Fluorescently Labeled Calmodulin and Tubulin in the Meiotic Apparatus of the Mouse Oocyte
}

\author{
Yukihisa Hamaguchi ${ }^{1}$, Fuyuki Iwasa ${ }^{2}$, Masaru Toriyama ${ }^{3, *}$ and \\ Hikoichi Sakai ${ }^{3}$ \\ ${ }^{1}$ Biological Laboratory, Tokyo Institute of Technology, Tokyo 152; 2 \\ Laboratory of Clinical Pharmacology, Suntory Institute for Biomedical \\ Research, Osaka 618, and ${ }^{3}$ Department of Biophysics and Biochemistry, Facul- \\ ty of Science, University of Tokyo, Tokyo 113, Japan
}

\begin{abstract}
The localizations of tubulin and calmodulin were investigated in the mouse oocyte during the second meiosis by fluorescently labeling and microinjecting these proteins prepared from porcine brain tissue. When injected, both tubulin and calmodulin were quickly incorporated into the preformed meiotic apparatus of the oocyte at metaphase. The localization of labeled tubulin was coincident with that of birefringence. However, the localization of labeled calmodulin was somewhat different: the fluorescence of calmodulin was intense in the polar regions of the spindle. After the chromosomes began to move, followed by parthenogenetic activation upon microinjection of a calcium buffer, these two fluorescent proteins, localized in the meiotic apparatus, moved to the interzonal region of the spindle during anaphase. At late anaphase and throughout telophase, calmodulin was excluded from the mid-bodylike structures in the interzonal region, whereas tubulin did accumulate in these structures.
\end{abstract}

Fluorescent analog cytochemistry (21) is useful for studying the dynamic behavior of cytoskeletal proteins during cell division (see ref. 6 as a review). In particular, fluorescently labeled tubulin and calmodulin have been used extensively to study the dynamics of these proteins in the mitotic apparatus during mitosis (6-8, $19,24)$.

The mouse unfertilized oocyte is a useful material for studying mitosis because it is transparent, stays at metaphase of the second meiosis for many hours after ovulation, and resumes mitosis upon artificial fertilization and parthenogenetic activation $(11,16-18,20,22)$. However, this material has not yet been utilized for studying the dynamics of the cytoskeleton in living cells.

In this study, we investigated the localizations of tubulin and calmodulin in the mouse oocyte by means of microinjection of these labeled proteins to determine the similarities and differences in their intracellular localization during the second meiosis.

\footnotetext{
* Present address: Fuculty of Liberal Arts, Shizuoka University, Shizuoka 422.
} 


\section{MATERIALS AND METHODS}

Female ICR mice were induced to superovulate by an injection of 5 IU of pregnant mare serum gonadotropin, followed $48 \mathrm{~h}$ later by an injection of 5 IU of human chorionic gonadotropin. Unfertilized oocytes were collected from the ampullae of excised oviducts. Cumulus cells were removed with $1 \mathrm{mg} / \mathrm{ml}$ hyaluronidase. Cumulus-free oocytes were maintained at $37^{\circ} \mathrm{C}$ in a modified TYH medium (see ref. 20$)(119 \mathrm{mM} \mathrm{NaCl} / 4.8 \mathrm{mM} \mathrm{KCl} / 1.7 \mathrm{mM}$ $\mathrm{CaCl}_{2} / 1.2 \mathrm{mM} \mathrm{MgSO}_{4} / 10 \mu \mathrm{M}$ EDTA $/ 1 \mathrm{mM}$ pyruvate $/ 1 \mathrm{mg}$ of glucose per $\mathrm{ml} / 4 \mathrm{mg}$ of bovine serum albumin per $\mathrm{ml} / 1.2 \mathrm{mM} \mathrm{KH}_{2} \mathrm{PO}_{4} / 5 \mathrm{mM} \mathrm{NaCO}_{3} / 20 \mathrm{mM}$ HEPES, $\mathrm{pH}$ 7.2).

Porcine brain calmodulin was fluorescently labeled with $\mathrm{N}$-(7-dimethylamino-4-
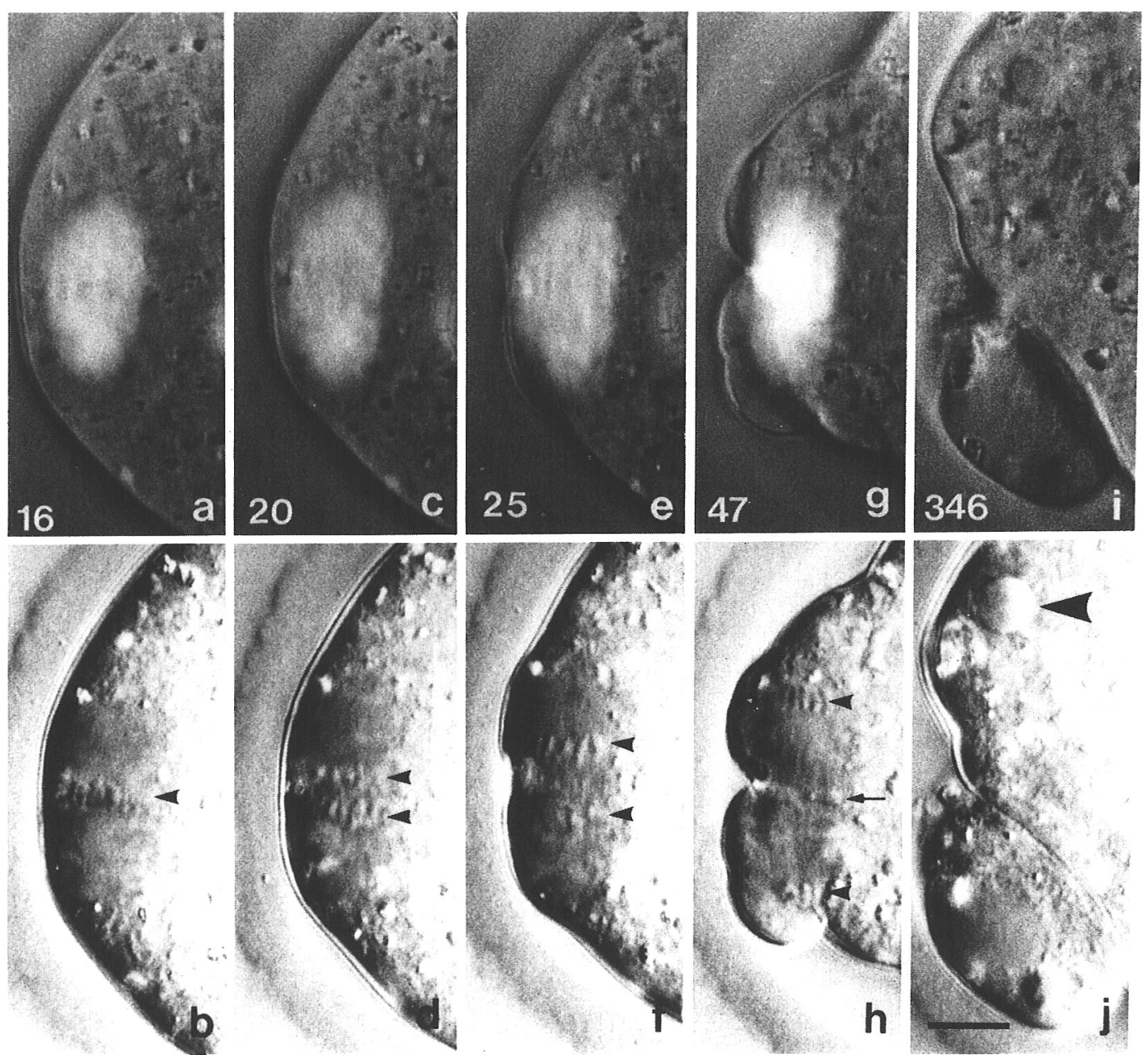

Fig. 1. A mouse oocyte during the second meiosis. The upper and lower rows show images of the meiotic spindle by polarization and differential interference microscopy, respectively, a, b metaphase. c$h$ anaphase. i, $\mathbf{j}$ telophase. Numbers represent time (min) after injection. Small arrowheads indicate chromosomes; a large arrowhead, the female pronucleus; the arrow, mid-bodylike structures. The bar corresponds to $10 \mu \mathrm{m}$. 
methylcoumarinyl)-maleimide, as described previously (7); porcine brain tubulin was fluorescently labeled with 5-(4,6-dichlorotriazin-2-yl)aminofluorescein, as described previously (8). For parthenogenetic activation, a $\mathrm{Ca}$ buffer solution of $0.2 \mathrm{M}$ N-hydroxyethylethylenediamine- $\mathrm{N}, \mathrm{N}^{\prime}, \mathrm{N}^{\prime}$-triacetic acid, $0.15 \mathrm{M} \mathrm{CaCO}_{3}$ and $0.05 \mathrm{M}$ PIPES (pH 7.0) was microinjected. Microinjection was carried out with a Narishige micromanipulator using a braking micropipette (9).

Observation was carried out at $37^{\circ} \mathrm{C}$ using a fluorescence microscope (Optiphot, Nikon, Tokyo) modified for use with differential interference optics (cf. ref. 8). We used a UVF 40x objective lens (NA 1.30) as the fluorescence and differential interference optics and a Plan 40x DIC lens (NA 0.65) as the polarization and differential interference optics, because the UVF $40 \mathrm{x}$ lens was inadequate for polarization microscopy when used at $37^{\circ} \mathrm{C}$.

Densitometric measurements were carried out along the spindle axis as follows. Photomicrographic negatives (Kodak 35-mm Tri-X film) were scanned with a projector (LP6, Sansei Koki, Ltd, Tokyo) equipped with a Nikon scanning stage. The scanning spot was a
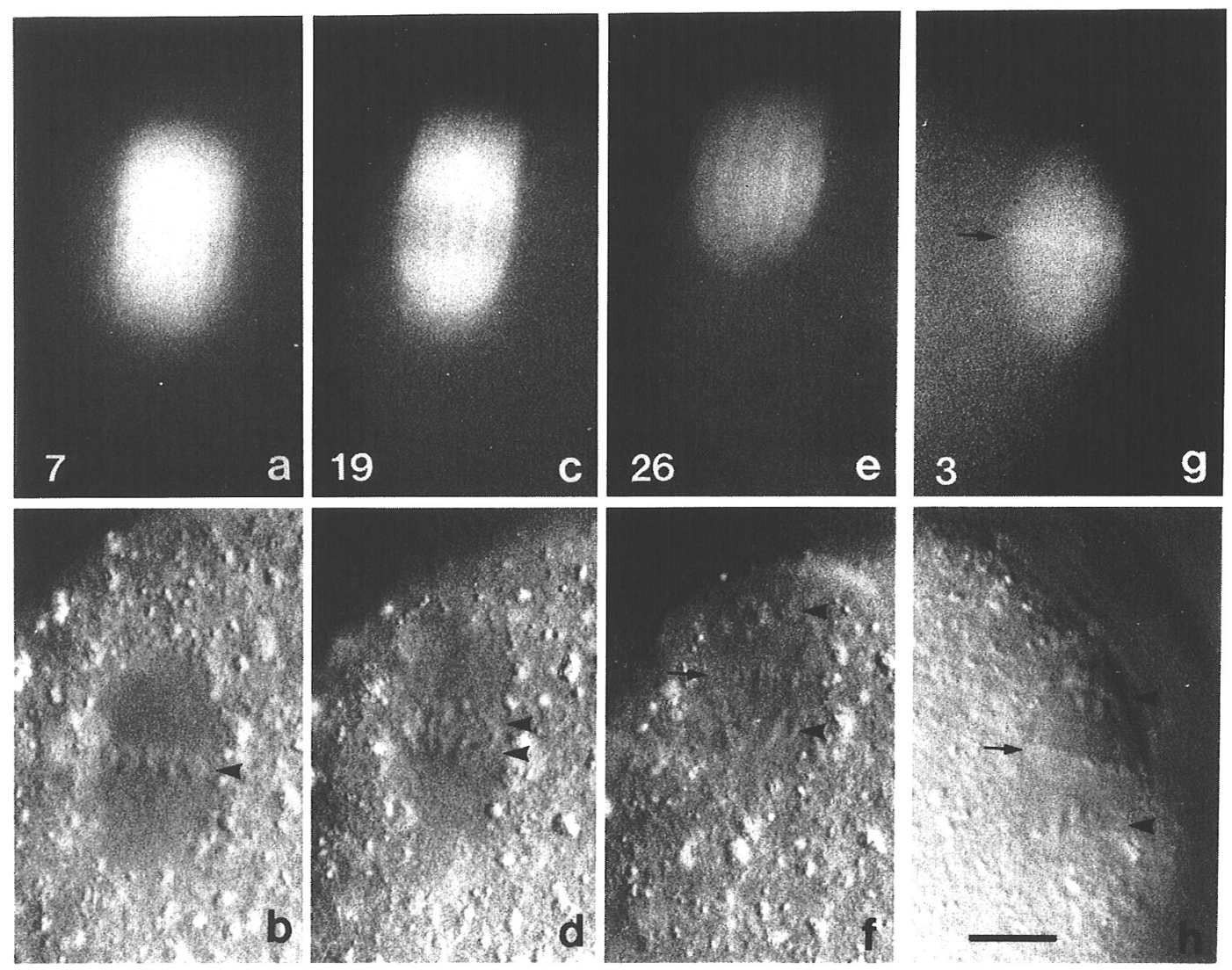

Fig. 2. Mouse oocytes during the second meiosis injected with the labeled tubulin. a, b metaphase. $c, d$ early anaphase. e, f mid-anaphase of an oocyte. $g, h$ late anaphase of another oocyte injected with the labeled tubulin at anaphase. The upper and lower rows show fluorescence and differential interference micrographs, respectively. Arrowheads indicate chromosomes; arrows, mid-bodylike structures; numbers, time (min) after injection. The bar corresponds to $10 \mu \mathrm{m}$. 
rectangle, $0.5 \times 1.0 \mu \mathrm{m}$ in size, whose length was placed perpendicular to the spindle axis. Light intensity of the rectangular area was measured with a photodiode (S1226-5BQ, Hamamatsu Photonics, Hamamatsu) and normalized against the darkest spot in the spindle and the spindle poles.

\section{RESULTS}

The meiotic apparatus at metaphase after ovulation and the second meiosis after activation by injection of a $\mathrm{Ca}$ buffer solution were observed in the same oocyte by alternately changing the polarization and differential interference optics (Fig. 1). Observations of the second meiosis of the mouse oocyte by differential interference and polarization microscopy were reported by Sorensen (18) and Sato and Blandau (16), respectively. The meiotic apparatus of the oocyte stays at metaphase. The spin-
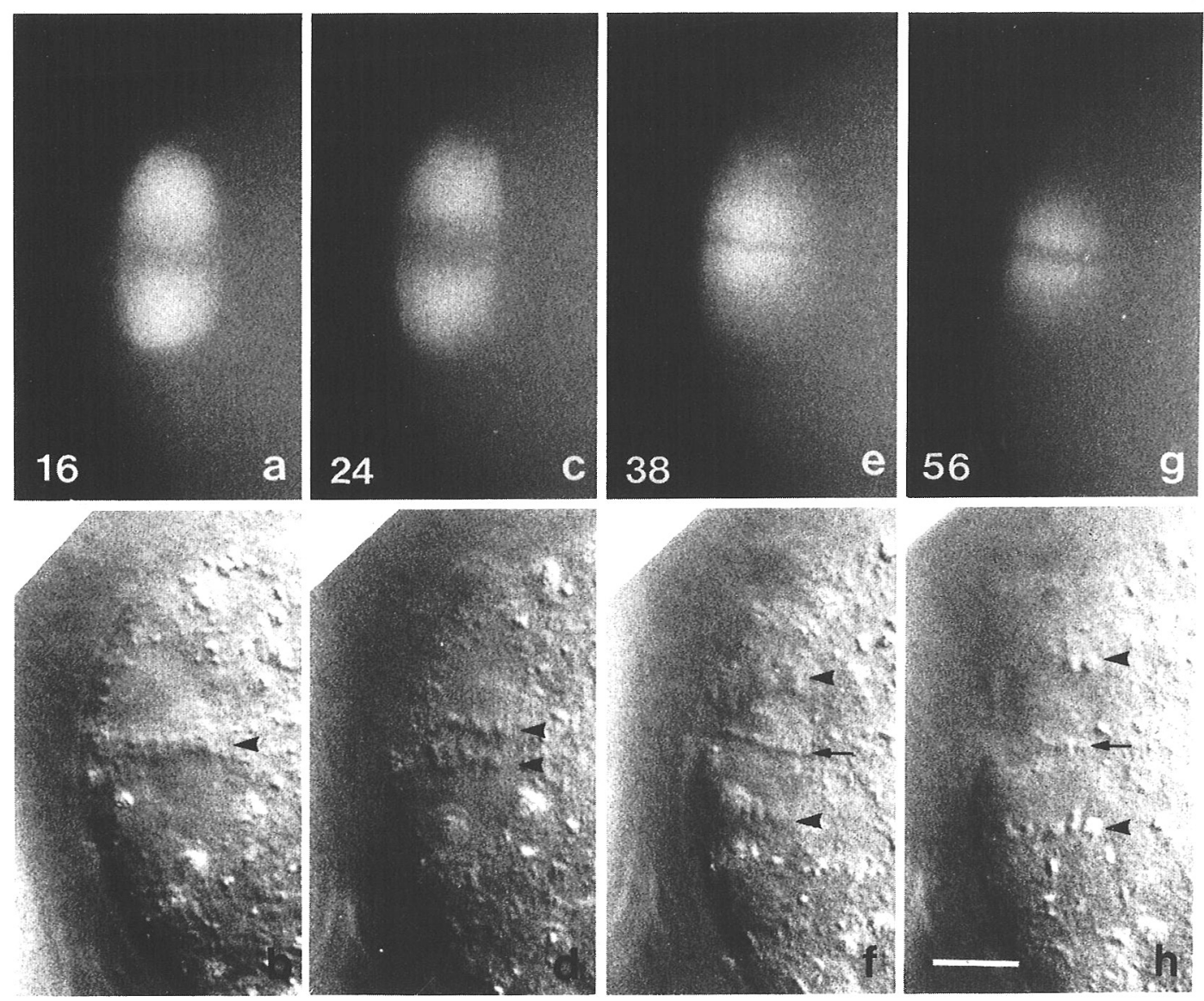

Fig. 3. A mouse oocyte during the second meiosis injected with the labeled calmodulin. The upper and lower rows show fluorescence and differential interference micrographs, respectively. a, b metaphase. c, d early anaphase. e, f mid-anaphase. g, h late anaphase. Arrowheads indicate chromosomes; arrows, mid-bodylike structures; the numbers, time (min) after injection. The bar corresponds to $10 \mu \mathrm{m}$. 
dle is anastral, barrel-shaped and attached to the oocyte cortex (Figs. 1a and b). Anaphase chromosome movement began 15-30 min after the injection of a $\mathrm{Ca}$ buffer solution (Figs. 1c and d). Birefringence (BR) of the half spindle decreased after mid-anaphase, but $B R$ of the interzonal region increased and remained throughout telophase (Figs. 1e-h). Mid-bodylike structures (MBLS) were formed in the middle of the interzonal region (Figs. $1 \mathrm{~g}$ and $\mathrm{h}$ ). The second polar body and the female pronucleus were formed, though the remaining intercellular bridge, called the mid-body (MB), still showed weak BR (Figs. 1i and j). The chromosome movement, changes in the spindle BR, and polar body formation occurred in the same manner as reported previously $(16,18)$.

When the fluorescently labeled tubulin or calmodulin was injected into the mouse oocyte at metaphase, it was incorporated quickly into the meiotic apparatus and became localized (Figs. $2 \mathrm{a}$ and $3 \mathrm{a}$ ). The localization of the fluorescent tubulin was coincident with the localization of BR (Figs. 1a and 2a). On the other hand,

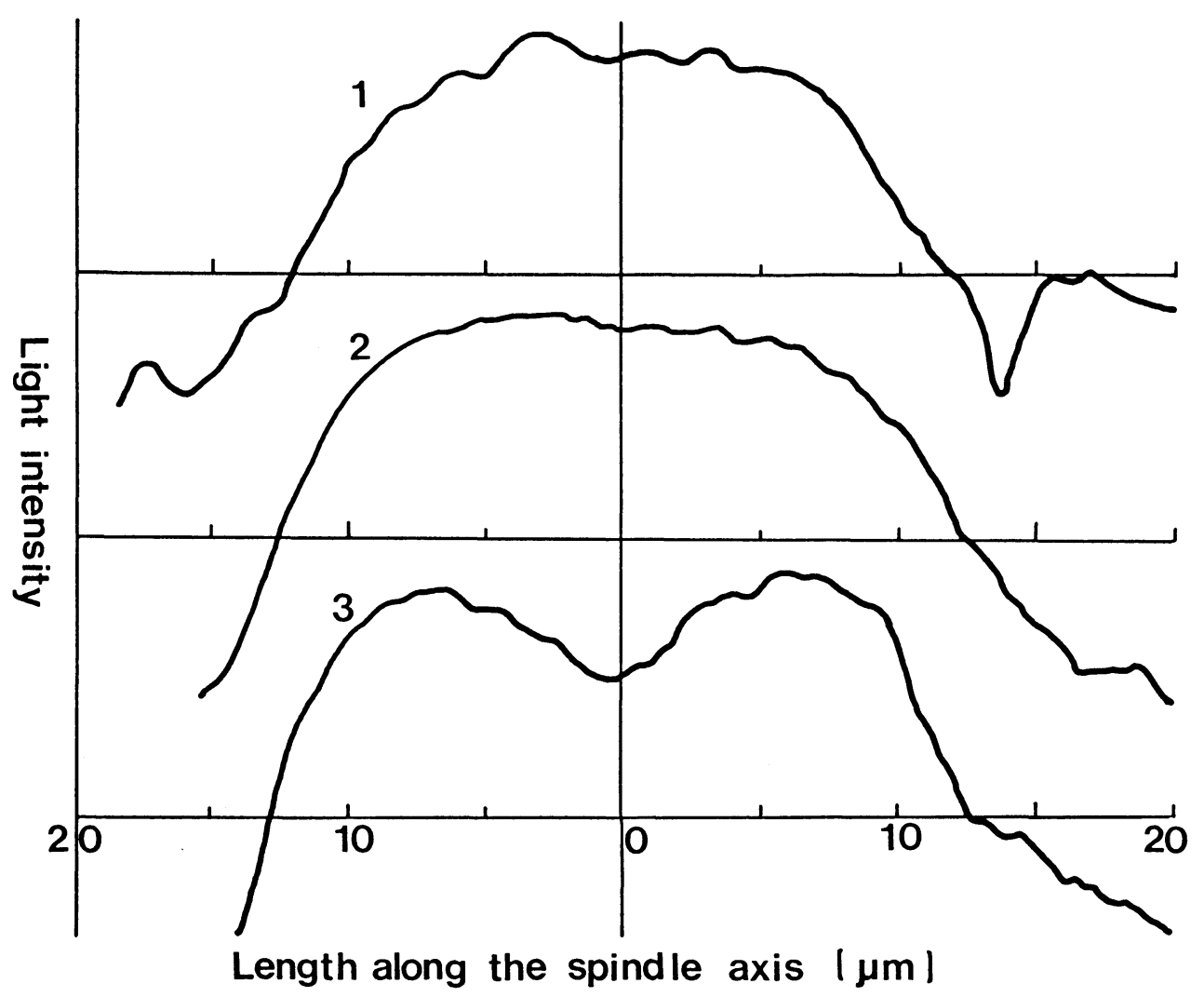

Fig. 4. Comparison among the distribution of birefringence (BR) (1), tubulin (2), and calmodulin (3) in the metaphase spindle by means of densitometric measurements. The light intensity of the spindle in photomicrographic negatives was measured along the axis from the upper pole to the lower pole and shows from the left to the right in these figures. Poles are represented by the crossing points of intensity curves and abscissae. 1, the distribution of BR in the spindle of Fig. 1a. 2, the distribution of fluorescence intensity of the labeled tubulin in the spindle of Fig. 2a. 3, the distribution of fluorescence intensity of the labeled calmodulin in the spindle of Fig. 3a. 
calmodulin accumulated more intensely near the polar regions of the spindle than in the equatorial region (Fig. 3a), showing a different localization from that of spindle BR. Figure 4 clearly shows the coincidence and difference among the localizations of BR, tubulin, and calmodulin in the metaphase spindle.

After anaphase began, the intensity of fluorescence of the labeled calmodulin and tubulin decreased in the half spindle but increased gradually with time in the interzonal region of the spindle (Figs. 2 and 3). After MBLS appeared in the center of the interzonal region, the fluorescent tubulin accumulated in the MBLS (Fig. 2g), while the fluorescent calmodulin was excluded from them (Figs. $3 \mathrm{e}$ and $\mathrm{g}$ ). The same results were obtained in eggs injected with the labeled tubulin and calmodulin at anaphase, as shown in Figs. $2 \mathrm{~g}$ and $\mathrm{h}$.

\section{DISCUSSION}

Fluorescently labeled calmodulin and tubulin were found to be quickly incorporated into the pre-formed meiotic apparatus of the mouse oocyte. Fluorescent tubulin was coincidentally localized with the birefringent spindle structure, reflecting microtubule distribution in the mitotic spindle of echinoderm eggs $(10,15)$. This fact indicates that microtubules in the mouse oocyte spindle, which is pre-formed and appeared changeless, exchange tubulin subunits quickly with the cytoplasmic pool of tubulin. Quick incorporation of exogenous tubulin in the mitotic apparatus has been reported in various cells (see ref. 6 for a review).

On the other hand, the fluorescent calmodulin was localized in the polar regions of the spindle, in contrast to the distribution of the fluorescent tubulin during metaphase and at the beginning of anaphase. This difference was previously noted and reported in various mitotic cells $(1,2,7,19,23,24)$, although the exogenous calmodulin can bind to tubulin $(12,13)$ or to microtubules $(4,5)$ in the mitotic apparatus. The accumulation of calmodulin in the polar regions of the spindle can be explained by the preferential binding of calmodulin to some calmodulin-binding proteins specifically localized in the polar regions of the spindle, as shown in mammalian cells (2).

Fluorescent immunocytochemistry using anti-tubulin antibodies did not detect tubulin in the MB or MBLS of the mouse oocyte during the late stage of the second meiosis $(17,22)$. However, the present results clearly indicate that the fluorescent tubulin was incorporated into the MBLS of mouse oocytes; this means that the microtubules in the MBLS can exchange subunits dynamically with the cytoplasmic pool of tubulin. In contrast, calmodulin was not incorporated into the MBLS, although it did accumulate in microtubules on either side of the structures. This finding is in agreement with the results reported using anti-calmodulin antibody (1, $4,23)$. Because interdigitating microtubules of the MB are embedded in electrondense materials observed by electron microscopy $(3,14)$, the microtubules of the MB or MBLS are considered to be coated with some microtubule-associated proteins. Thus, this may prevent calmodulin in living cells and anti-tubulin antibodies in fixed cells from binding to microtubules.

Acknowledgment. We wish to thank Professor Emeritus Yukio Hiramoto of Tokyo Institute of Technology for his valuable advice and critical reading of the manuscript. We thank Dr. M. Yokoyama for his patient instruction in the handling of mouse oocytes.

This work was supported by Grants-in-Aid from the Ministry of Education, Science, and Culture of Japan to Y. Hamaguchi (62540538) and H. Sakai (60065005). 


\section{REFERENCES}

1. Andersen, B., M. Osborn and K. Weber. Specific visualization of the distribution of the calcium dependent regulatory protein of cyclic nucleotide phosphodiesterase (modulator protein) in tissue culture cells by immunofluorescence microscopy: Mitosis and intercellular bridges. Cytobiologie 17, 354-364, 1978

2. Brady, R.C., F. CABRAL and J.R. DEDman. Identification of a 52-kD calmodulin-binding protein associated with the mitotic spindle apparatus in mammalian cells. J. Cell Biol. 103, 1855-1861, 1986

3. BuCK, R.C. and J.M. Tisdale. The fine structure of the mid-body of the rat erythroblast. J. Cell Biol. 13, 109-115, 1962

4. DeEry, W.J., A.R. Means and B.R. BrinkLeY. Calmodulin-microtubule association in cultured mammalian cells. J. Cell Biol. 98, 904-910, 1984

5. De Mey, J., M. Moeremans, G. Geuens, R. Nuydens, H. Van Belle and M. De Brabander. Immunocytochemical evidence for the association of calmodulin with microtubules of the mitotic apparatus. in Microtubules and Microtubule Inhibitors, ed. De Brabander, M. and J. De MeY. Elsevier/North-Holland Biochemical Press, Amsterdam, pp. 227-240, 1980

6. Hamaguchi, $\mathrm{Y}$. In vivo cytochemistry in cell division. Zool. Sci. 5, 545-552, 1988

7. HamaguCHI, Y. and F. IwASA. Localization of fluorescently labeled calmodulin in living sea urchin eggs during early development. Biomed. Res. 1, 502-509, 1980

8. Hamaguchi, Y., M. Toriyama, H. Sakai and Y. Hiramoto. Redistribution of fluorescently labeled tubulin in the mitotic apparatus of sand dollar eggs and the effects of taxol. Cell Struct. Funct. 12, 43-52, 1987

9. Нiramoto, Y. A method of microinjection. Exp. Cell Res. 87, 403-406, 1974

10. Hiramoto, Y., Y. Hamaguchi, Y. Shoj,, T.E. Schroeder, S. Shimoda and S. Nakamura. Quantitative studies on the polarization optical properties of living cells. II. The role of microtubules in birefringence of the spindle of the sea urchin egg. J. Cell Biol. 89, 121-130, 1981

11. Kaufman, M.H. The experimental production of mammalian parthenogenetic embryos. in Methods in Mammalian Reproduction ed. Daniel, J.C., Academic Press, pp. 21-47, 1978

12. Kumagai, H. and E. Nishida. The interaction between calcium-dependent regulator protein of cyclic nucleotide phosphodiesterase and microtubule proteins. J. Biochem. (Tokyo), 85, 12671274,1979

13. Kumagai, H., E. Nishida and H. SaKaI. The interaction between calmodulin and microtubule proteins. VI. Quantitative analysis of the binding between calmodulin and tubulin dimer. $J$. Biochem. (Tokyo), 91, 1329-1336, 1982

14. Mullins, J.M. and J.R. MCINTosh. Isolation and initial characterization of the mammalian midbody. J. Cell Biol. 94, 654-661, 1982

15. Sato, H., G.W. Ellis and S. Inoue. Microtubular origin of mitotic spindle birefringence. Demonstration of the applicability of Wiener's equation. J. Cell Biol. 67, 501-517, 1975

16. Sato, K. and R.J. Blandau. Second meiotic division and polar body formation in mouse eggs fertilized in vitro. Gamete Res. 2, 283-293, 1979

17. Schatten, G., C. Simerly and H. Schatten. Microtubule configurations during fertilization, mitosis, and early development in the mouse and the requirement for egg microtubule-mediated motility during mammalian fertilization. Proc. Nat. Acad. Sci. USA 82, 4152-4156, 1985

18. Sorensen, R.A. Cinemicrography of mouse oocyte maturation utilizing Nomarski differential-interference microscopy. Amer. J. Anat. 136, 265-276, 1973

19. Stemple, D.L., S.C. Sweet, M.J. Welsh and J.R. Mcintosh. Dynamics of a fluorescent calmodulin analog in the mammalian mitotic spindle at metaphase. Cell Motil. Cytoskeleton $\mathbf{9}$, 231-242, 1988

20. Toyoda, Y., M. Yokoyama and T. Hoshi. Studies on the fertilization of mouse eggs in vitro. I. In vitro fertilization of eggs by fresh epididymal sperm. Jap. J. Animal. Reprod. 16, 147-151, 1971

21. WANG, Y.L., J.M. HeIPLE and D.L. TAYLOR. Fluorescent analog cytochemistry of contractile proteins. Method in Cell Biol. 25, 1-11, 1982

22. WASSERman, P.M. and K. Fujtwara. Immunofluorescent anti-tubulin staining of spindles during meiotic maturation of mouse oocytes in vitro. J. Cell Sci. 29, 171-188, 1978

23. Welsh, M.J., J.R. Dedman, B.R. Brinkley and A.R. Means. Calcium-dependent regulator pro- 
tein: Localization in mitotic apparatus of eukaryotic cells. Proc. Natl. Acad. Sci. USA 75, 18671871,1978

24. Zavortink, M., M.J. Welsh and J.R. Mcintosh. The distribution of calmodulin in living cells. Exp. Cell Res. 149, 375-385, 1983

(Received for publication, January 12, 1989) 